- This paper compares global job satisfaction scores and reported workload for practitioners working in the GDS and the PDS, both in fully NHS and part NHS/part private practices.

- Data analysis identifies 'restriction in being able to deliver quality care' as a key factor related to dentists' job satisfaction.

- Practitioners working in high caries areas felt more restricted in being able to deliver quality care than those working in areas with less disease.

- Practitioners working in mixed NHS/private practices were more highly orientated towards 'developing clinical skills' than practitioners working in wholly NHS practices, either in the GDS or the PDS.

\title{
Facets of job satisfaction of dental practitioners working in different organisational settings in England
}

\author{
R. V. Harris, ${ }_{1}^{1}$ A. Ashcroft, ${ }_{1}^{2}$ G. Burnside, ${ }_{1}^{3}$ J. M. Dancer, ${ }_{1}^{4}$ D. Smith ${ }^{5}$ and B. Grieveson ${ }^{6}$
}

Introduction Before April 2006, English dentists were either working as an NHS general dental service (GDS) practitioner (fee-per-item, no local contractual obligations); an NHS personal dental service (PDS) practitioner (block contract with the primary care trust (PCT)); a private practitioner (either fee-per-item or capitation-based, independent of the PCT); or in a situation where they were mixing their NHS work (either under the GDS or PDS arrangements) with private work.

Objectives To a) investigate the extent of the mix of NHS and private work in English dentists working in the GDS and PDS, b) to compare global job satisfaction, and c) to compare facets of job satisfaction for practitioners working in the different organisational settings of PDS practices, GDS practices and practices where there is a mix of NHS and private provision.

Method A questionnaire was sent to 684 practitioners, containing 83 attitudinal statements relating to job facets, a global job satisfaction score and questions concerning workload.

Results Response rate was 65.2\%. More PDS than GDS dentists were found to treat the majority of their patients under the NHS. GDS dentists working fully in the NHS were least likely to be satisfied with their job, followed by PDS practitioners and then GDS dentists working in mixed NHS/private practices. Private practitioners were the most satisfied. Conclusion Differences between GDS, PDS and private practitioners

\footnotetext{
${ }^{1}$ Senior Lecturer, ${ }^{2}$ Lecturer in Health Psychology, ${ }^{3}$ Lecturer in Dental Statistics, Liverpool University School of Dental Sciences, 5th Floor, Dental Hospital, Pembroke Place, Liverpool, L3 5PS; ${ }^{4}$ Management School, University of Liverpool, Chatham Street, Liverpool, L69 7ZH; ${ }^{5}$ Professor of Management/Director of Research, Department of Management, University of Glasgow Business School, Gilbert Scott Building, Glasgow, G12 800; ${ }^{6}$ Postgraduate Dental Dean, Mersey Deanery, Regatta Place, Brunswick Business Park, Summers Road, Liverpool, L3 4BL

${ }^{*}$ Correspondence to: Dr Rebecca V. Harris

Email: harrisrv@liv.ac.uk
}

Online article number E1

Refereed Paper - accepted 25 September 2007

DOI: $10.1038 /$ bdj.2007.1204

${ }^{\oplus}$ British Dental Journal 2008; 204: E1 were found in global job satisfaction and in the facets of job satisfaction related to restriction in being able to provide quality care, control of work and developing clinical skills.

\section{INTRODUCTION}

Healthcare in the UK is predominantly state-financed, with the National Health Service (NHS) one of the largest organisations in Europe. It was founded in 1948 on the principles of providing a health service available to all on the basis of need, not ability to pay, and was funded through general taxation. Although these principles are still upheld, with a budget of over $£ 49$ billion and constant financial pressures on the system through the demands of increasing public expectations, medical advances and an ageing population, cost containment and cost efficiency are real issues. ${ }^{1}$ Since $2002,80 \%$ of the NHS budget has been held by primary care trusts (PCTs), which are local organisations charged with assessing local needs and commissioning healthcare for the local population. ${ }^{2}$ Given that manpower costs account for some $65 \%$ of NHS costs, attention has been recently focused on ways to maximise the performance of NHS staff. ${ }^{3}$

Job satisfaction has long been recognised as a key factor determining productivity, as summarised by the statement 'a satisfied worker is a good worker'. ${ }^{4}$ Job satisfaction is also important in relation to turnover and absenteeism. Within the NHS, these issues have been brought into sharp focus in recent years with the whole reform agenda and the changing of consultant, general medical practitioner and general dental practitioner (GDP) contracts. Dentists' job satisfaction is of particular interest at the present time, since over recent years there has been a steady shift of practitioners from National Health Service provision into the private sector. ${ }^{5}$ In 2001, a report from the House of Commons Select Committee ${ }^{6}$ concluded that the fee-per-item system of remuneration underpinning the general dental service (GDS) system was a main cause of dissatisfaction amongst practitioners. 
Legislation was subsequently introduced ${ }^{7}$ to allow personal dental services (PDS) practices to be established. Dental practitioners in these practices were no longer remunerated using a fee-per-item system, but by a new system of block monthly payments, based on agreed levels of activity set out in locally negotiated contracts with their PCT. By May 2005, $24 \%$ of dental practices had transferred from the former GDS to become PDS practices, although in some PCT areas there were considerably more PDS practices than in others. It has been suggested that PDS arrangements provided a means of changing the culture of primary dental care provision to one based on quality rather than activity and cost, although outcome evaluations have been limited due to methodological problems associated with a lack of suitable comparator practices. ${ }^{8}$ Although there is some evidence that a less invasive style of dental treatment is undertaken by practitioners working under PDS arrangements, ${ }^{9}$ no quantitative data on dentist job satisfaction is available.

In general terms, job satisfaction can be defined as an individual's general attitude toward his or her job. Clearly, a person with a high level of job satisfaction invariably holds positive attitudes toward their job, whilst a person who is dissatisfied holds negative attitudes about their job. ${ }^{4}$ Job satisfaction is therefore not a single entity, but a complex set of interrelationships of tasks, roles, responsibilities, interactions, incentives and rewards. ${ }^{10}$ What makes measuring job satisfaction difficult, is that it is possible to be satisfied with some aspects of a job and at the same time be dissatisfied with others. ${ }^{11}$ As a consequence, most recognised measures of job satisfaction have involved the assessment of a number of discrete elements contributing to job satisfaction - often called 'job facets'. ${ }^{10}$ Multi-dimensional scales allow the investigator to identify the specific areas where job satisfaction is high or low. The subscales can also be used to determine which aspects of job satisfaction are most affected by an intervention.

Whilst there has been a lot of previous research on stress in dentistry, ${ }^{12,13}$ the study of job satisfaction has received less attention. Stress and job satisfaction are different, although related, concepts. Stress is defined as a dynamic condition in which an individual is confronted with an opportunity, constraint, or demand related to what he or she desires and for which the outcome is perceived to be both uncertain and important. ${ }^{4}$ Therefore stress is typically associated with constraints and demands - the former preventing you to do something you desire, the latter referring to the loss of something desired. For example, in the context of a dental practice, 'running behind schedule' and 'working constraints set by the NHS' are aspects of the job of a dental practitioner identified as stressors. ${ }^{13}$ The relationship between these elements and job satisfaction are however, poorly understood. Cooper et al. ${ }^{14}$ in a study of general dental practitioners did find a relationship between the elements of job stress 'time and scheduling pressures' and 'negative patient perceptions' and job dissatisfaction, although only $11 \%$ of the variance in the job satisfaction measure used was explained. It is likely that whilst stressors may partly influence job satisfaction, there are also other dimensions which determine job satisfaction in dental practitioners. The use of multi-dimensional scales of job satisfaction helps to identify these other ingredients.

Two previous studies have developed measures involving subscales of dentists' job satisfaction facets, ${ }^{15,16}$ both of which were undertaken in the USA. The most widely used measure is the Dentists' Satisfaction Survey, ${ }^{15}$ which was used in a previous UK study of the job satisfaction of general dental practitioners (GDPs) in Staffordshire. ${ }^{17}$ However, dentists' job satisfaction is inevitably influenced by cultural values as well as the system in which the dentist works, and so it is important to use a tool which has been developed and validated for use in a UK setting. For example, issues such as the pressures experienced working under a state-funded system will not necessarily be reflected in a measure developed in a context where the dental practice system is predominantly delivered in the private sector. This study therefore uses a new psychometrically tested tool to measure dental practitioner job satisfaction which has been developed for use in a UK population. ${ }^{18}$

Study of dentists' job satisfaction in a setting at a time where general practice dentists were working under a variety of systems of remuneration and governance provides a unique opportunity to gain insight into the impact of the health system on dentists' job satisfaction. Dentists in the UK were either working as an NHS GDS practitioner (fee-per-item, no local contractual obligations), an NHS PDS practitioner (block contract with the PCT), a private practitioner (either fee-per-item or capitation-based, independent of the PCT), or in a situation where they were mixing their NHS work (either under the GDS or PDS arrangements) with private work. The aims of this study were therefore threefold: a) to investigate the extent of the mix of NHS and private work in practitioners working in the GDS and PDS, b) to compare the general (global) job satisfaction, and c) to compare the facets of job satisfaction for dental practitioners working in the different organisational settings of PDS practices, GDS practices and practices where there is a mix of NHS and private provision.

Although in April 2006 the arrangements governing the GDS were brought to an end with the introduction of a new dental contract, the new arrangements to some extent follow a PDS model in that all dental practitioners now work to a contract held by the local PCT, with remuneration no longer based on a fee-per-item system. A study of the impact on practitioner job satisfaction of work within the PDS and old GDS systems will give an early indication of how practitioners will react to changes in the general dental practice system. It is recognised that current problems with access to primary dental care stem from a reduction of GDPs' time spent working within the NHS $;^{19}$ and so an important question facing both the dental profession and politicians, is whether the new system will address the issues of concern for practitioners which underlie their move into the private sector. Investigating facets of job satisfaction in the different organisational settings of PDS, GDS, mixed PDS/private and GDS/private practices will help to predict the impact of the new dental contract on the general dental practice system.

\section{METHOD}

A questionnaire containing 131 statements (items) was developed following taped semi-structured interviews with 13 dentists working in different systems in the UK (PDS, GDS and private practice). They included both male and female dentists and associate dentists as well as practice owners. Items were also included from a previously validated dentists' job satisfaction questionnaire in the USA. ${ }^{15}$ All items were written in 


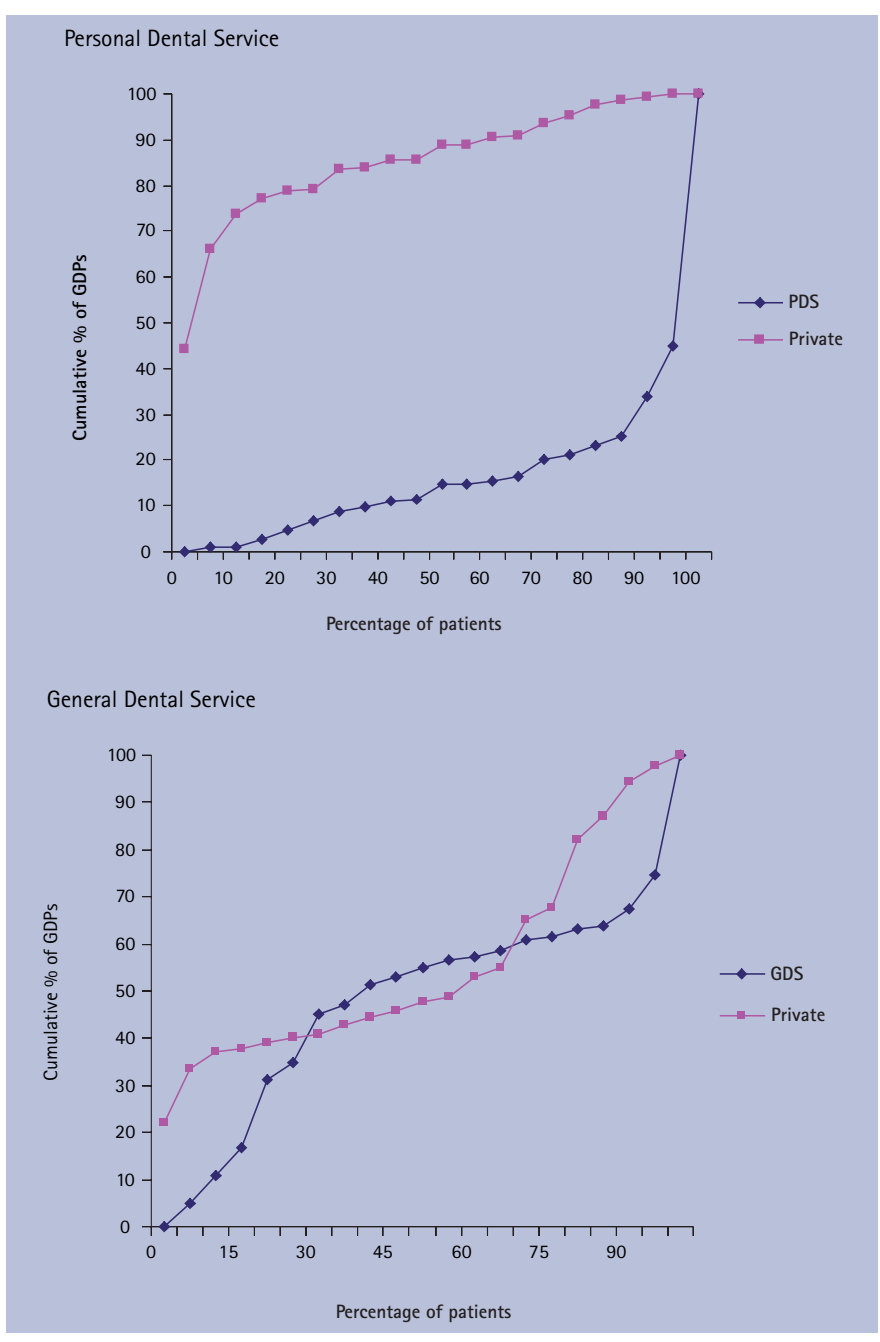

Fig. 1 Mixing of private and NHS provision in the general dental service (GDS) and personal dental service (PDS) settings

a five-point Likert format with a score range from 1 (strongly disagree) to 5 (strongly agree). The item pool was refined after 30 GDPs completed the questionnaire and item analysis was carried out, reducing the number of attitudinal statements in the questionnaire to 83. Reduction of the number of statements in the questionnaire by item analysis meant that only statements which were correlated with the questionnaire responses as a whole were used in a shorter, final version. Twenty-five GDPs also completed repeat questionnaires. Test/retest analysis on the items in the final version of the questionnaire indicated a reasonably high level of reliability $(\mathrm{r}=0.78)$. The practitioners chosen for this pilot stage were a convenience sample and were excluded from the main study.

The questionnaire also contained some other questions relating to perceived workload, as well as a global job satisfaction score. Workload was measured as a response to a single question 'a) I am not busy enough, I can meet a higher demand for care; b) I am neither not busy enough nor too busy and am able to meet the current demand for care and could not cope with more; c) I am too busy and am not able to meet the demand for care'. Global job satisfaction was measured in response to the question 'How satisfied are you with your job?' on a five-point Likert scale from 1 = very dissatisfied to 5 = very satisfied.

The questionnaire was then sent to all dental practitioners working in 14 primary care trusts in three areas of England
(Cheshire and Merseyside, Cumbria and Lancashire, Shropshire and Staffordshire). Practitioners were informed that responses were confidential and coding of practitioners preserved anonymity whilst allowing for follow up of non-responders. The covering letter was signed by both the University research team lead and the Postgraduate Dean.

The PCTs were selected to ensure a balance between high and low disease levels, and rural and urban areas. High DMFT areas were those where in 2003/4, five-year-olds had a mean DMFT of 2.0 or more, and low DMFT areas were those where the mean DMFT of five-year-olds was 1.5 or less. ${ }^{20}$ Using a sampling grid, areas with both high and low disease levels were chosen in rural and urban areas. Rural areas were defined using a rural definition developed by the Rural Evidence Research Centre, ${ }^{21}$ which is based on a settlement definition and defines 'significant rural areas' as places where more than $26 \%$ of the population live in rural settlements or market towns. All rural PCTs chosen had 37\% or more of the population living in such areas, whilst urban PCTs sampled had 17\% or less living in such areas.

The sampling grid also took account of the fact that in some PCTs there were a relatively high proportion of practices working under PDS arrangements, whilst in others, this was low. Therefore within the PCTs sampled, half were identified as high PDS areas $(60 \%$ or more dental practices in PDS in May 2005) and half were low PDS areas (less than 30\% of dental practices in PDS in May 2005). Questionnaires were sent to a total of 684 practitioners between January and March 2006.

Data analysis involved a further reduction of the number of items by item analysis in order to develop internal reliability by identifying and then rejecting statements which were negatively correlated with the questionnaire responses as a whole. Item-total correlations, means and Cronbach's alpha were calculated for each item. Items with poor internal reliability were discarded before further analysis. Factor analysis (PCA) was then undertaken, which groups statements that are answered in similar ways, identified as those with an Eigenvalue of 1.0 or over. The statements within each factor were examined to determine the common threads which existed and an appropriate descriptor was given to the factor.

Multiple regression analysis was carried out to identify personal attributes and practice characteristics significantly associated with factors. A stepwise forward selection model was used, where the most significant variables enter the model one by one, until there are no further significant variables. Therefore, the final models only contain those variables which were significantly associated with the factors. Since numbers of completely private practitioners were low, these were excluded from this analysis. Gender, single handed/multi-dentist practice, practice owner/associate, rural/urban, high/low DMFT area, qualified before/after 1987, and whether a practice was GDS/PDS/PDS + private, GDS + private were all entered into the models. The effect of clustering within PCTs was tested using the multilevel modelling package MLwiN. Statistical testing of factor means comparing practitioners working GDS, PDS and private systems was undertaken using analysis of variance.

\section{RESULTS}

After a total of three mailings, 446 (65.2\%) practitioners returned questionnaires, with respondents comprising of 
$292(65.5 \%)$ males and 154 (34.5\%) females. There were six incomplete returns, leaving 440 (64.3\%) for analysis. Thirtynine of these reported working completely within former GDS arrangements, 122 worked within PDS arrangements, 119 worked partly in the GDS system and also provided some care on a private basis, 148 provided care partly as a PDS and partly on a private basis, and 12 provided care completely within the private sector.

\section{Mixing of NHS and private provision}

Figure 1 demonstrates the range of mixing of NHS and private provision within both the GDS and PDS settings. The horizontal axis shows the percentage of patients that practitioners stated that they treated privately or via the NHS respectively. The vertical axis shows the cumulative proportion of practitioners who stated they treated more than this percentage of patients in each way respectively. The difference between GDS and PDS practices is striking, in that whereas the NHS plot for PDS practitioners shows that most still concentrate on NHS work, with three quarters of practitioners treating $85 \%$ or more of their patients within the NHS, for practitioners still working in the GDS, the distribution is quite different. Less than $40 \%$ of practitioners working in the GDS treat $85 \%$ of their patients on the NHS.

It was also found that practitioners working in mixed NHS/ private practices within the GDS system reported that on average 13.3\% ( $S D=23.1$ ) of their workload comprised of NHS fee-paying adults, in comparison to practitioners working in mixed PDS/private practices where a reported mean of 37.0\% $(S D=23.3)$ of their workload comprised of this group. Dentists working in a GDS/private system saw a correspondingly greater proportion of fee-paying adults on a private basis, compared to those working in a PDS/private system.

\section{Global job satisfaction}

In reply to a question about their job satisfaction as a whole, 46.2\% (18) dentists working in wholly NHS practices under GDS arrangements were satisfied or very satisfied, compared to $59.8 \%$ (73) of dentists working in wholly NHS practices under PDS arrangements. A similar proportion of PDS practitioners working in mixed NHS/private practices felt satisfied or very satisfied $(56.1 \%, 83)$, although significantly more practitioners $(69.8 \%, 83)$ who worked in practices under GDS arrangements but also had a mix of private work, felt this way about their job. Although numbers of completely private practitioners were low, as many as $83.3 \%$ (10) felt satisfied or very satisfied with their job.

\section{Facets of job satisfaction}

Analysis of job satisfaction according to various job facets identifies which aspects of one's job is most likely to discriminate between those feeling satisfied and dissatisfied with their job. Item analysis of attitudinal statements reduced the item pool to 40 items. Factor analysis identified six item groupings as distinguishable job facets (Table 1). The factors were as follows: Factor 1: restriction in being able to provide quality care; Factor 2: respect from being a dentist; Factor 3: control of work; Factor 4: running a dental practice; Factor 5: developing clinical skills; Factor 6: helping people. The overall Cronbach's alpha was 0.88. Table 1 lists the statements featured
Table 1 Item loadings for the six factors identified by the factor analysis ordered by the coherence of the items in the factor

Items within the factor

Item loadings

Factor 1: Restriction in being able to provide quality care $(\alpha=0.88)$

\begin{tabular}{|c|c|}
\hline I do not have enough time to devote to my patients' needs & 0.796 \\
\hline I feel I am on a treadmill in my job & 0.783 \\
\hline I am not happy with my current work-rate & 0.761 \\
\hline I lack opportunities to provide quality care & 0.739 \\
\hline $\begin{array}{l}\text { My power to decide what treatment I should provide } \\
\text { for my patients is restricted }\end{array}$ & 0.723 \\
\hline I have the freedom to decide how long to spend on treatments & 0.639 \\
\hline I am often unable to meet patients' expectations & 0.637 \\
\hline I feel stressed in my job & 0.632 \\
\hline The majority of my patients do not value dentistry & 0.548 \\
\hline $\begin{array}{l}\text { I feel that the opportunity for me to develop a specialist } \\
\text { interest is limited }\end{array}$ & 0.537 \\
\hline I earn as much as I feel I should for the work I do & 0.485 \\
\hline
\end{tabular}

Factor 2: Respect from being a dentist $(\alpha=0.80)$

I feel satisfied when I gain respect from other dentists

I work hard to be a respected person in the community 0.738

Being a respected person in the community is satisfying

I work hard in order to gain respect from patients

Gaining respect from other dentists is a reason I work hard

I work hard to gain respect from staff in the practice

Factor 3: Control of work $(\alpha=0.80)$

\begin{tabular}{|c|c|}
\hline Being in control of which patients I treat is satisfying & 0.759 \\
\hline Being able to control which patients I treat motivates me & 0.678 \\
\hline $\begin{array}{l}\text { Being able to decide how many patients I treat per } \\
\text { session is satisfying }\end{array}$ & 0.663 \\
\hline Being able to determine my hours of work motivates me & 0.640 \\
\hline $\begin{array}{l}\text { Being able to make my own decisions regarding clinical } \\
\text { work is satisfying }\end{array}$ & 0.571 \\
\hline $\begin{array}{l}\text { Having the flexibility to determine my income level } \\
\text { motivates me }\end{array}$ & 0.550 \\
\hline $\begin{array}{l}\text { Earning an income which is sufficient for my family's } \\
\text { needs is satisfying }\end{array}$ & 0.512 \\
\hline \multicolumn{2}{|l|}{ Factor 4: Running a dental practice $(\alpha=0.81)$} \\
\hline $\begin{array}{l}\text { Being able to make my own decisions about how the } \\
\text { practice is run is satisfying }\end{array}$ & 0.774 \\
\hline Being able to develop the practice as a business is satisfying & 0.749 \\
\hline $\begin{array}{l}\text { I am satisfied with being able to make my own decisions } \\
\text { about how the practice is run }\end{array}$ & 0.725 \\
\hline I work hard to maintain a buoyant practice & 0.613 \\
\hline $\begin{array}{l}\text { Being able to make my own decisions about how the } \\
\text { practice is run motivates me to work hard }\end{array}$ & 0.604 \\
\hline $\begin{array}{l}\text { I feel motivated to create a nice atmosphere amongst } \\
\text { staff in the practice }\end{array}$ & 0.459 \\
\hline
\end{tabular}




\begin{tabular}{|c|c|}
\hline \multicolumn{2}{|l|}{ Continued from page 4} \\
\hline \multicolumn{2}{|l|}{ Factor 5: Developing clinical skills $(\alpha=0.81)$} \\
\hline Having time to improve my clinical skills is satisfying & 0.804 \\
\hline I am driven to keep up with current advances in dentistry & 0.740 \\
\hline I am driven to produce high quality clinical work & 0.652 \\
\hline Being able to keep abreast of advances in dentistry is satisfying & 0.649 \\
\hline $\begin{array}{l}\text { Having time to improve my clinical skills motivates me } \\
\text { to work hard }\end{array}$ & 0.536 \\
\hline \multicolumn{2}{|l|}{ Factor 6: Helping people $(\alpha=0.75)$} \\
\hline Being able to relieve people's pain is satisfying & 0.783 \\
\hline I am motivated by being able to relieve people's pain & 0.781 \\
\hline Being able to help people in my job is satisfying & 0.722 \\
\hline $\begin{array}{l}\text { I find it satisfying to show patients how to achieve good } \\
\text { dental health }\end{array}$ & 0.459 \\
\hline Providing a service for all those who need it is satisfying & 0.437 \\
\hline
\end{tabular}

in each of the factors, together with their item loading, which is a measure of how closely the statement was identified with the factor. For example, the statement 'I do not have enough time to devote to my patients' needs' is particularly highly identified with Factor 1 (restriction in being able to provide quality care).

The strength of feeling of the practitioner in relation to the factors is measured by the means from the response categories of all items in the factor, with 1 = strongly disagree, 2 = disagree, 3 = neither agree nor disagree, $4=$ agree and $5=$ strongly agree. Therefore a high mean score indicates a positive attitude towards this factor. The attitude scale for negative statements such as 'I do not have enough time to devote to my patients' needs' was reversed prior to the analysis so that a high mean score indicates a positive attitude in all cases, including Factor 1.

The modelled effect of clustering within PCTs was very low for all six factors and not significantly different from zero. Therefore, all subsequent analyses are presented ignoring the clustering effect. Differences were seen between practitioners working in different types of organisational settings with respect to Factor 1, Factor 3, Factor 4 and Factor 5 (Table 2). GDS practitioners working on a completely NHS basis were least likely to have a positive attitude towards Factor 1; or in other words, they were more likely to identify with feeling restricted in being able to deliver quality care. PDS practitioners working either on an NHS basis or partly in the NHS and partly on a private basis had a slightly more positive attitude, although less so than GDS practitioners working in a mixed NHS/private practice.

Practitioners working in high DMFT areas had a mean score of 2.71 ( $\mathrm{SD}=0.71$ ) for Factor 1 compared to those working in low DMFT areas (mean $=3.02, \mathrm{SD}=0.75$ ), indicating that dentists in high DMFT areas felt more restricted in being able to deliver quality care. No such differences were evident between high and low DMFT areas for other factors.

\section{Regression model analysis}

The associations between each factor and all practice characteristics and personal characteristics were assessed using stepwise multiple regression models. Separate models were fitted for the six factors and only those variables significantly associated with the factor are included in each of the models. Results of the regression analyses are presented in Table 3. In most cases the variables which entered the model were dichotomous values, with the significance value in the table giving the result of the comparison between the two values. The direction of the estimated beta coefficient (positive or negative) indicates whether the value of the variable listed in the table (eg female dentist) was associated with the factor in a positive direction. For example, female dentists were more likely to rate highly the job facets relating to 'respect from being a dentist' and 'helping people' than male dentists. The variable practice type was not a dichotomous variable, but had four possible values (GDS only, GDS + private, PDS + private, PDS only). The significance value for the variable 'practice type' as a whole is given in the table where this variable entered the model, and also for the comparison between the reference category of GDS only and the other three subgroups of practice types.

The regression analysis showed that type of practice system, time since qualification, whether the practice was in a high or low disease area, and whether the dentist was a practice owner or associate were all significantly associated with Factor 1.

Taking practitioners working solely within the GDS system as a reference category, fully NHS practitioners in the GDS were most likely to feel restricted in providing quality care, followed by practitioners either working in fully NHS PDS practices or part PDS/private practices. Practitioners working in a mixed GDS/private system were least likely to feel restricted in providing quality care. Practitioners who qualified more recently, practice owners and those working in high DMFT areas were also more likely to feel restricted in providing quality care. No significant differences were apparent between rural and urban practitioners.

GDS practitioners working in a mixed NHS/private practice emerged as the only statistically significant variable with respect to Factor 3 (control at work) in the regression model. The organisational setting also emerged as being important in Factor 5 (developing clinical skills). When other variables were taken into account, both GDS and PDS practitioners working in mixed NHS/private practices showed a more positive attitude towards developing clinical skills than practitioners working in wholly NHS practices, either in the GDS or the PDS.

Gender emerged as a significant variable in the models for Factor 2 (females having more positive attitudes towards 'respect from being a dentist' than males), Factor 5 and Factor 6 (females having more positive attitudes towards 'developing clinical skills' and 'helping people' than males).

\section{Workload}

When practitioners were asked to rate their workload in terms of identifying with one of three statements concerning whether they felt a) not busy enough, b) neither too busy nor not busy enough or c) too busy, 53.9\% (21) of wholly NHS GDS practitioners rated themselves as too busy, compared to 50\% (61) of practitioners working in wholly NHS PDS practices. Only 
Table 2 Mean factor scores for each factor comparing practitioners working within different types of general dental practice

\begin{tabular}{|c|c|c|c|c|c|}
\hline Factor & $\begin{array}{l}\text { Mean (SD) GDS only } \\
\text { practitioners } \\
n=39\end{array}$ & $\begin{array}{l}\text { Mean (SD) GDS + } \\
\text { private practitioners } \\
\mathrm{n}=119\end{array}$ & $\begin{array}{l}\text { Mean (SD) PDS only } \\
\text { practitioners } \\
n=122\end{array}$ & $\begin{array}{l}\text { Mean }(S D) \text { PDS }+ \\
\text { private practitioners } \\
n=148\end{array}$ & $\begin{array}{l}\text { Mean }(S D) \text { private } \\
\text { only practitioners } \\
n=12\end{array}$ \\
\hline $\begin{array}{l}\text { Factor } 1 \\
\text { Restriction in being able to pro- } \\
\text { vide quality care } \\
p<0.001^{*}\end{array}$ & $2.46(0.62)$ & $3.30(0.75)$ & $2.74(0.65)$ & $2.83(0.68)$ & $3.91(0.63)$ \\
\hline $\begin{array}{l}\text { Factor } 2 \\
\text { Respect from being a dentist } \\
p=0.775\end{array}$ & $3.67(0.59)$ & $3.72(0.52)$ & $3.72(0.52)$ & $3.69(0.55)$ & $3.51(0.67)$ \\
\hline $\begin{array}{l}\text { Factor } 3 \\
\text { Control of work } \\
p<0.001^{*}\end{array}$ & $3.64(0.61)$ & $3.87(0.49)$ & $3.54(0.54)$ & $3.63(0.62)$ & $3.92(0.43)$ \\
\hline $\begin{array}{l}\text { Factor } 4 \\
\text { Running a dental practice } \\
p=0.002^{*}\end{array}$ & $3.81(0.53)$ & $3.94(0.51)$ & $3.68(0.52)$ & $3.69(0.64)$ & $3.72(0.69)$ \\
\hline $\begin{array}{l}\text { Factor } 5 \\
\text { Developing clinical skills } \\
p<0.001^{*}\end{array}$ & $3.65(0.57)$ & $3.99(0.61)$ & $4.07(0.51)$ & $3.87(0.55)$ & $4.38(0.55)$ \\
\hline $\begin{array}{l}\text { Factor } 6 \\
\text { Helping people } \\
p=0.757\end{array}$ & $4.06(0.53)$ & $4.05(0.54)$ & $4.07(0.51)$ & $3.99(0.49)$ & $4.02(0.51)$ \\
\hline
\end{tabular}

$41.2 \%$ (61) and 23.5\% (28) of practitioners working in a mixed NHS/private system in the PDS and the GDS respectively reported feeling too busy.

When asked to estimate how many patients they would see within a morning session, for example during the period from 9am to $12.30 \mathrm{pm}$, those groups who were more likely to perceive themselves as being 'too busy' not surprisingly reported seeing higher numbers of patients per session. GDS practitioners who were working completely in the NHS saw a mean of 17.53 ( $\mathrm{SD}=4.23$ ) patients, compared to PDS practitioners in NHS practices who saw a mean of $15.26(\mathrm{SD}=4.42)$. PDS practitioners working in NHS/private practices saw a mean of 14.95 (SD $=4.19$ ) patients and GDS practitioners in NHS/private practices saw a mean of $13.41(\mathrm{SD}=4.65)$ patients. Practitioners working in completely private practices saw a mean of $9.42(\mathrm{SD}=2.68)$ patients, although there were low numbers of practitioners in this group.

\section{DISCUSSION}

\section{Generalisability}

Whilst the participants involved in this study were located in three Strategic Health Authority areas, sampling and data analysis was undertaken to take account of key variables such as urban/rural areas, high/low DMFT areas and high PDS/low PDS conversion rate areas, so that the findings could be usefully generalised to other areas of the country. The response rate for the questionnaire was reasonable for a study of this nature, given the sensitive nature of some of the questions. Indeed, the response rate exceeded the minimum response rate criterion (60\%) recommended by Babbie. ${ }^{22}$ The sample also appears to reflect the gender balance of the wider population of UK dental practitioners, in that 35\% of respondents were female, compared to $37 \%$ of dentists on the UK General Dental Council (GDC) ${ }^{23}$ list at the end of 2005 who were female.

\section{Benefits of the PDS system}

Results indicate that the recent changes in the UK's general dental practice system with respect to the creation of PDS practices are associated with benefits in terms of practitioner job satisfaction. NHS dental practitioners working on this basis were more likely to be satisfied with their job. Changing the system of remuneration away from a fee-per-item arrangement appears also to be associated with a reduction in workload in terms of numbers of patients seen per session and practitioners consequently express feeling less pressured.

\section{Restriction in providing quality care and the shift from NHS to private work}

The results indicate that the overall rating of job satisfaction is significantly correlated with all six facets of job satisfaction identified in the analysis, but particularly highly associated with Factor 1 (restriction in being able to provide quality care). Factor analysis is used to identify statements which represent a common psychological concept. Thus the statements which make up Factor 1 (Table 1) are all ingredients of a sentiment where the practitioner feels driven by workload pressures to compromise on delivering care at standards perceived to be acceptable both by professional standards and by patients themselves.

These findings echo some of the findings of the Health Select Committee, ${ }^{6}$ which concluded that 'Despite the problems with the remuneration system, actual level of income is not the reason many dentists cite for leaving the NHS. Their concern is that providing comprehensive high quality dental care to appropriate standards has become increasingly difficult under the GDS contract'. Results of this study show that practitioners choosing to mix NHS and private care (both in the GDS and PDS system) were more likely to express a strong attitude towards finding the clinical aspects of their work satisfying 
(Factor 5). This suggests that for those motivated particularly by achieving a good clinical outcome, there is a greater impetus to work within the private sector.

\section{Restriction of professional autonomy}

Feeling in control of their work is another job facet considered to be important by some practitioners. GDS practitioners working in mixed NHS/private practices were found to value professional autonomy more highly than other groups. A study of dental practitioners in the Netherlands ${ }^{24}$ also found that concerns relating to professional autonomy were, as was found in this study, poorly correlated with dentist characteristics such as gender and time since qualification. However, it is possible that this value varies with the outlook of the individual, and for some practitioners, having control at work is a key job characteristic which satisfies higher needs and contributes to job satisfaction..$^{25}$ That the group of practitioners holding the more positive attitudes towards Factor 3 'control' were those who were currently operating to the greatest extent within the private sector, is therefore probably indicative of the choices made by these practitioners in the light of the restrictions operating within the NHS system, on account of their relatively strong orientation towards this job facet.

Regression analysis also showed that GDS practitioners working in mixed NHS/private practices were least likely to identify with Factor 1 (feeling restricted in providing quality care). They were less likely to identify with Factor 1 than PDS practitioners working in mixed NHS/private practices - which at first sight is surprising. However, when the extent of mixing NHS and private care of these two groups of practitioners is compared, it becomes apparent that GDS practitioners in mixed NHS/private practices do in fact have a higher proportion of private work than the PDS group. Therefore whilst it appears encouraging that PDS practitioners feel more positive than GDS practitioners with respect to Factor 1, and consequently in relation to their job satisfaction as a whole, this does not match the extent to which practitioners with a reduced NHS commitment experience.

\section{Implications of the findings}

What will this mean in an era where both the PDS and the former GDS systems have been consigned to history, and a new system based on Units of Dental Activity established? The findings suggest that if the new system allows practitioners to work at a pace which allows them to feel satisfied in providing appropriate standards of care, and the difference between the NHS system and the private sector is not any greater in this respect, the drift away from the NHS sector may stabilise. Motivational theory acknowledges that internal drivers such as achievement are more powerful motivators than external incentives such as income. ${ }^{25}$ This study underlines the importance of acknowledging the fulfilment of these types of need in dental practitioners in order to retain the workforce within the NHS sector. Younger practitioners were found to identify more strongly with Factor 1 attitudes than those who had been qualified for longer, which underlines the importance of addressing such issues within the new system in order to retain an NHS workforce for the future. This has real implications for policy makers, and also for those involved in training the dentists of the future. Currently dentists are trained to undertake clinical

\begin{tabular}{|c|c|c|c|}
\hline $\begin{array}{l}\text { Demographic } \\
\text { variable }\end{array}$ & $\begin{array}{l}\text { Estimated Beta } \\
\text { coefficient }\end{array}$ & $\mathrm{t}$ & $\mathrm{p}$-value \\
\hline \multicolumn{4}{|c|}{$\begin{array}{l}\text { Factor 1: Restriction in being able to provide quality care } \\
\text { (adjusted } \mathrm{R}^{2}=0.162 \text { ) }\end{array}$} \\
\hline $\begin{array}{l}\text { Practice type } \\
\text { GDS + private* } \\
\text { PDS + private* } \\
\text { PDS only* }\end{array}$ & $\begin{array}{l}0.792 \\
0.345 \\
0.290\end{array}$ & $\begin{array}{l}6.27 \\
2.78 \\
2.32\end{array}$ & $\begin{array}{l}<0.001 \\
<0.001 \\
0.006 \\
0.021\end{array}$ \\
\hline $\begin{array}{l}\text { Qualified } 20 \text { years } \\
\text { or more }\end{array}$ & 0.219 & 3.07 & 0.002 \\
\hline High DMFT area & -0.237 & -3.26 & 0.001 \\
\hline Practice owner & -0.177 & -2.44 & 0.015 \\
\hline \multicolumn{4}{|c|}{ Factor 2: Respect from being a dentist (adjusted $\mathrm{R}^{2}=0.016$ ) } \\
\hline Female dentist & 0.163 & 2.79 & 0.006 \\
\hline \multicolumn{4}{|c|}{ Factor 3: Control of work (adjusted $R^{2}=0.038$ ) } \\
\hline $\begin{array}{l}\text { Practice type } \\
\text { GDS + private* } \\
\text { PDS + private* } \\
\text { PDS only* }\end{array}$ & $\begin{array}{l}0.233 \\
0.009 \\
-0.071\end{array}$ & $\begin{array}{l}2.24 \\
0.09 \\
0.68\end{array}$ & $\begin{array}{l}<0.001 \\
0.026 \\
0.930 \\
0.495\end{array}$ \\
\hline \multicolumn{4}{|c|}{ Factor 4: Running a dental practice (adjusted $\mathrm{R}^{2}=0.288$ ) } \\
\hline Practice owner & 0.622 & 12.95 & $<0.001$ \\
\hline \multicolumn{4}{|c|}{ Factor 5: Developing clinical skills (adjusted $R^{2}=0.040$ ) } \\
\hline $\begin{array}{l}\text { Practice type } \\
\text { GDS + private* } \\
\text { PDS + private* } \\
\text { PDS only* }\end{array}$ & $\begin{array}{l}0.390 \\
0.265 \\
0.156\end{array}$ & $\begin{array}{l}3.57 \\
2.50 \\
1.45\end{array}$ & $\begin{array}{l}0.004 \\
<0.001 \\
0.013 \\
0.149\end{array}$ \\
\hline Female dentist & 0.171 & 2.82 & 0.005 \\
\hline \multicolumn{4}{|c|}{ Factor 6: Helping people (adjusted $\mathrm{R}^{2}=0.010$ ) } \\
\hline Female dentist & 0.119 & 2.27 & 0.024 \\
\hline
\end{tabular}

work to exacting technical standards, and the imbibing of professional attitudes to their work is an important component of undergraduate courses. Is it surprising that many find restrictions of subsequent work within an NHS system produces inner conflicts and dissatisfaction?

\section{International implications}

The new multi-dimensional measure of dentists' job satisfaction $^{18}$ used in the study does appear to reflect well the concerns of UK practitioners. Discernable differences in the six factors in the study by gender, organisational setting (GDS/PDS/private), years from qualification, high/low DMFT area of the practice, and practice ownership were detected, and could be interpreted. The factorial structure which emerged was also in keeping with the findings in a study by Calnan et al. ${ }^{26}$ who identified ethical and altruistic concerns that the needs of their patients could not be met by an NHS system as a key reason for dentists' shift towards practising in the private sector.

The factorial structure contains some commonalities with other scales of dentists' job satisfaction used in internationally. The Dentists' Satisfaction Survey ${ }^{15}$ contains items grouped into 12 job facets, with the majority of the variance in job satisfaction among dentists predicted by 'respect received from being 
a dentist'. Other facets found to be related to job satisfaction (but to a lesser extent) were: the process of delivering care, income derived from dentistry, relationships with patients, and reduced levels of job-related stress. The fact that the factorial structure in the job satisfaction scale developed in the UK contains a dimension related specifically to problems experienced with the health system in which UK practitioners work (restriction in being able to provide quality care), underlines the importance of developing measures which take account of international differences in culture and health service factors, particularly where such measures are used to inform policy and monitor the impact of changes to the healthcare system. This paper illustrates the impact of the healthcare system on the job satisfaction of dental practitioners by looking at differences between practitioners working in the GDS, PDS and private systems in the UK at one point in time.

1. Ham C. Financing the NHS. BMJ 1998; 316: 212-213.

2. Batchelor P. The historical and political background to the proposals for local commissioning of primary dental care by primary care trusts. Primary Dent Care 2005; 12: 11-14.

3. Davis $\mathrm{C}$, Anand $\mathrm{P}$, Artigas L et al. Links between governance, incentives and outcomes: a review of the literature. Report for the NCCSDO, 2005. www.sdo.Ishtm. ac.uk/files/project/66-final-report.pdf

4. Robbins S P. Organizational behaviour: concepts, controversies, application. 5th ed. pp 142. New Jersey: Prentice-Hall International, 1998.

5. Lynch $M$, Calnan $M$. The changing public/private mix in dentistry in the UK: a supply-side perspective. Health Econ 2003; 12: 309-321.

6. House of Commons Health Select Committee. Access to NHS dentistry. London: HMSO, 2001. ISBN 0102192014.

7. National Health Service (Primary Care) Act 1997. London: HMSO, 1997.

8. Goodwin N, Morris A J M, Hill K B, McLeod H S, Burke FJ T, Hall A C. National evaluation of personal dental services (PDS) pilots: main findings and policy implications. Br Dent J 2003; 195: 640-643.

9. Best $H$, Newton T. Evaluation of the personal dental services (wave 1) for Lambeth, Southwark, and Lewisham Primary Care Trusts - Part 2: retrospective analyses of treatment and other dental record data. J Eval Clin Pract 2005; 11: 229-236.
10. Cameron S. Job satisfaction: the concept and its measurement. Michigan: Work Research Unit, 1973.

11. Herzberg F, Mauser B, Snydeman B B. The motivation to work. New York: Wiley, 1959.

12. Humphris $G$ M, Cooper C L. New stressors for GDPs in the past ten years: a qualitative study. Br Dent J 1998; 185: 404-406.

13. Wilson R F, Coward PY, Capewell J, Laidler T L, Rigby A C, Shaw T J. Perceived sources of occupational stress in general dental practitioners. Br Dent J 1998; 184: 499-502.

14. Cooper C L, Watts J, Baglioni A J, Kelly M. Occupational stress amongst general practice dentists. J Occup Psychol 1988; 61: 163-174.

15. Shugars D A, DiMatteo R, Hays R D, Cretin S, Johnson J D. Professional satisfaction among California general dentists. J Dent Educ 1990; 54: 661-669.

16. Chapko M K, Bergner M, Beach B, Green K, Milgrom P. Development of a measure of job satisfaction for dentists and dental auxiliaries. Community Dent Oral Epidemiol 1986; 14: 76-79.

17. Gilmour J, Stewardson D A, Shugars D A, Burke F J T. An assessment of career satisfaction among a group of general dental practitioners in Staffordshire. $\mathrm{Br}$ Dent J 2005; 198: 701-704.

18. Harris R V, Ashcroft A, Burnside G, Dancer J M, Smith D, Grieveson B. Measurement of attitudes of UK dental practitioners to core job constructs. Community Dent Health (in press).

19. Modernising NHS dentistry - implementing the NHS plan. London: Department of Health, 2000.

20. Pitts N B, Boyles J, Nugent Z J, Thomas N, Pine C M. The dental caries experience of 5-year-old children in England and Wales (2003/4) and in Scotland (2002/3). Surveys co-ordinated by the British Association for the Study of Community Dentistry. Community Dent Health 2005; 22: 46-56.

21. Rural definition. www.defra.gov.uk/rural/ruralstats/rural-definition.htm. London: Department for Environment, Food and Rural Affairs, 2005.

22. Babbie E. Survey research methods. 2nd ed. Belmont, CA: Sage, 1993.

23. General Dental Council. Annual report 2005. London: GDC, 2006. http://www. gdc-uk.org/News+publications+and+events/Publications/General+information +leaflets/Annual+Report+2005.htm

24. van der Sanden W J M, Mettes D G, Plasschaert A J M, van't Hof M A, Grol R P T $M$, Verdonschot $E \mathrm{H}$. Clinical practice guidelines in dentistry: opinions of dental practitioners on their contribution to the quality of dental care. Qual Saf Health Care 2003: 12: 107-111.

25. Cooper R. How jobs motivate. In Weir M (ed) Job satisfaction: challenge and response in modern Britain. Glasgow: Fontana, 1976.

26. Calnan M, Silvester S, Manley G, Taylor-Goody P. Doing business in the NHS: exploring dentists' decisions to practise in the public and private sectors. Sociol Health IIIn 2000; 22: 742-764. 